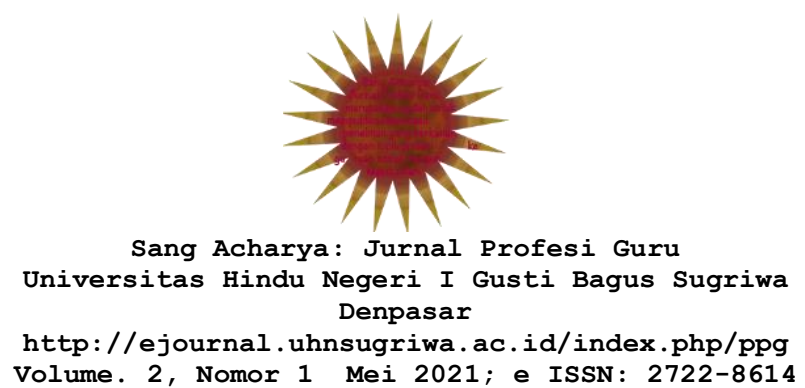

\title{
CECIMPEDAN SEBAGAI SARANA BELAJAR KOSA KATA BAHASA BALI SERTA PENGENALAN LINGKUNGAN PADA ANAK USIA SEKOLAH DASAR
}

\author{
I Putu Wiyasa; I Gusti Ayu Puspita Dewi; Gusti Nyoman Mastini \\ Universitas Hindu Negeri I Gusti Bagus Denpasar \\ putuwiyasa@gmail.com; gustiayupuspitadewi@gmail.com
}

\begin{abstract}
Abstrak
Pulau Bali terkenal dengan budaya dan beragam kearifan lokal di setiap masing masing daerahnya. Salah satu produk budaya Bali adalah bahasa Bali. Bahasa Bali adalah salah satu bahasa daerah yang sampai saat ini masih digunakan oleh masyarakat penuturnya. Beralih dari bahasa, masyarakat Bali juga memiliki berbagai bentuk sastra lisan. Sastra lisan yang cukup dikenal adalah Basita Paribasa Bali, yang merurut para ahli dibagi menjadi beberapa bentuk. Salah satu diantaranya adalah cecimpedan. Dari segi bentuk, cecimpedan sama dengan teka-teki berbahasa Bali (Anom dkk, 2014), artinya ada penanya dan ada penjawab. Para leluhur yang menciptakan kesusastraan ini tentu memiliki fungsinya tersendiri. Apa sajakah fungsi dari permaian cecimpedan pada anak anak? Hasil pembahasan fungsi yang terdapat di dalam cecimpedan adalah (1) menyenangkan anak-anak, (2) melatih ketangkasan berpikir anak-anak secara spontan, (3) melestarikan kosakata agar tidak punah, (4) melatih anak-anak berpikir kreatif, dan (5) menambah wawasan lingkungan.
\end{abstract}

Kata kunci : cecimpedan, kosa kata bahasa Bali, pengenalan lingkungan.

\section{Pendahuluan}

Bahasa Bali merupakan salah satu bahasa daerah yang sampai saat ini masih digunakan oleh masyarakat penuturnya. Berdasarkan jumlah penuturnya bahasa Bali dapat digolongkan ke dalam bahasa daerah yang besar, karena memiliki jumlah penutur lebih dari satu juta jiwa (Bawa, 1981 : 7). Bahasa Bali sebagai salah satu bahasa daerah di kawasan Nusantara sudah sejak dahulu menarik perhatian, karena Bahasa Bali masih memiliki fungsi dan kedudukan yang cukup potensial dalam kehidupan sehari-hari, baik sebagai bahasa ibu, bahasa pergaulan, bahasa media cetak, bahasa pengantar di tingkat permulaan sekolah dasar maupun sebagai sarana penyalur aspek seni budaya Bali. Dalam kehidupan sehari-hari bahasa Bali masih tetap digunakan sebagai alat komunikasi bagi penuturnya baik dalam situasi resmi maupun situasi tidak resmi.

Pulau Bali memilki beragam budaya dan kearifan lokal pada masing-masing daerahnya. Oleh karena itulah Pulau Bali menjadi pusat tujuan wisata internasional. Dengan berkembangnya industri pariwisata dan pesatnya perkembangan teknologi, juga akan mempengaruhi budaya Bali. Pada zaman modern ini banyak orang Bali yang mulai meninggalkan budaya Bali. Contoh kecilnya, para orang tua lebih banyak berkomunikasi dan berinteraksi dengan anak-anaknya menggunakan bahasa Indonesia dan mulai jarang 


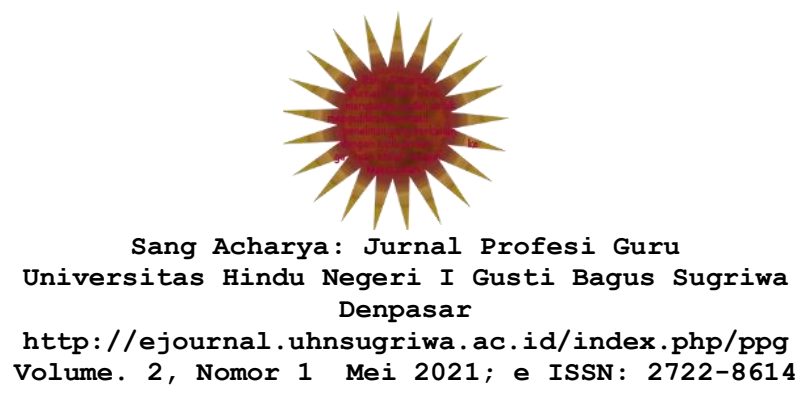

menggunakan bahasa daerah Bali. Tak hanya itu, dahulu sarana bermain anak-anak tidak seperti pada zaman mileneal ini, yang lebih banyak menggunakan perangkat teknologi tinggi (high tecnology). Walaupun demikian, para orang tua di Bali memiliki banyak inisiatif terkait dengan permainan anak-anak. Masyarakat di Bali memiliki berbagai bentuk sastra lisan. Salah satu diantaranya adalah cecimpedan yang merupakan salah satu bagian dari Paribasa Bali (sastra lisan). Dari segi bentuk, cecimpedan sama dengan teka-teki (Anom dkk, 2014).

Permainan cecimpedan ini sangat menarik untuk dimainkan oleh anak-anak, karena berupa teka-teki yang berkaitan dengan alam sekitar serta pertanyaan dan petunjuk teka-teki ini menggunakan bahasa Bali. Salah satu tokoh budaya dan sastra Bali tradisional, I Wayan Simpen A.B (2010 : 49) mengatakan bahwa cecimpedan dipakai untuk mengasah ketangkasan pada saat bersendu gurau. Cecimpedan berasal dari kata 'cimped' yang artinya 'terka', mendapat akhiran -an dan di-dwipurwa-kan menjadi 'cecimpedan' yang artinya tebak-tebakan. Cecimpedan tidak hanya memiliki unsur humor, namun juga terdapat pelajaran mengenai lingkungan sekitar. Banyak hal yang dijadikan sebagai bahan teka-teki pada cecimpedan, seperti tanaman, perabotan rumah tangga, hewan dan yang lainnya.

Cecimpedan juga merupakan salah satu materi pelajaran bahasa Bali yang sudah diajarkan disekolah-sekolah. Dahulu, cecimpedan biasanya dimainkan oleh orang tua dan anaknya. Di dalam permainan, orang tua memberikan teka-teki dan sang anak bertugas untuk menjawab. Hal ini juga sangat baik dilakukan untuk menjalin hubungan yang erat antara anak dan orang tua. Seiring dengan perkembangan zaman, sangat disayangkan jika permainan ini hanya menjadi bahan ajar di sekolah dan sangat jarang dimainkan orang tua untuk anak mereka. Dengan berkembangnya teknologi pada era modern ini, maka dikhawatirkan bermain cecimpedan akan punah dan tidak lagi dikenal oleh generasi muda. Oleh karena itu, bermain cecimpedan perlu diperkenalkan serta disosialisasikan kepada generasi muda. Tak hanya untuk mengasah ketangkasan berpikir, bermain cecimpedan juga memiliki fungsi lainnya.

Dalam permainan cecimpedan, anak-anak akan belajar berbagai hal yang berguna untuk meningkatkan kemampuan berimajinasi dan kecerdasan anak. Beberapa hal yang akan diperoleh ketika bermain cecimpedan, dapat meningkatkan kecerdasan kognitif anak, anakanak dapat belajar kosa kata bahasa Bali secara tidak langsung, belajar imajinasi dengan membayangkan isi dari teka-teki dan mengaitkannya dengan lingkungan sekitar, meningkatkan kecerdasan anak melalui proses bermain yang menyenangkan (bermain sambil belajar), belajar mengemukakan pendapat (bersosialisasi) serta berkompetisi dengan rekan sepermainan. Sejak beberapa tahun yang lalu cecimpedan mulai dilombakan pada anak-anak tingkat sekolah dasar dari tingkat kecamatan hingga tingkat provinsi melalui Pesta Kesenian Bali sebagai salah satu usaha dalam melestarikan budaya Bali. Diharapkan dengan adanya lomba serta pelatihan cecimpedan dapat terus memberikan suatu wadah bagi anak-anak dalam mempelajari dan menghargai salah satu kearifan lokal budaya Bali. 


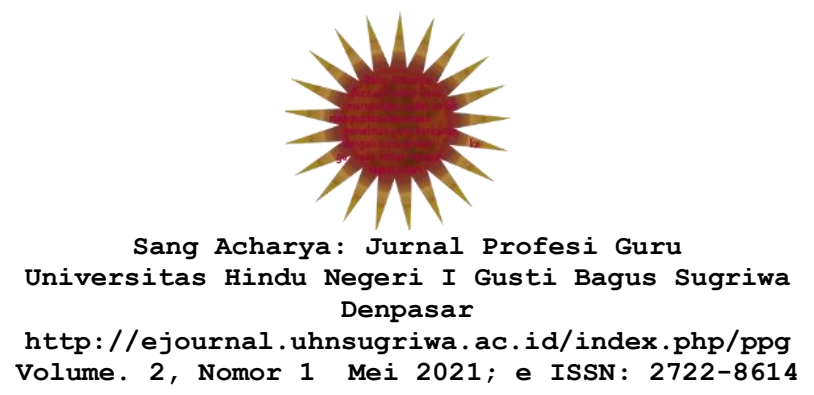

\section{Pembahasan}

Pada zaman dahulu, bermain cecimpedan biasanya dilakukan ketika malam selesai anak-anak belajar. Mereka berkumpul dengan berbagai aktivitas tradisional, seperti mendengarkan satua (dongeng), macecimpedan, dan sebagainya. Puncak kesenangan anakanak bermain ketika bulan purnama. Dalam macecimpedan mereka membagi diri menjadi dua kelompok. Ada yang bertanya dan kelompok yang lain menjawab. Ketika pertanyaan tidak terjawab, kelompok yang kalah akan dikenai hukuman. Jenis hukumannya bervariasi sesuai dengan kesepakatan mereka, hukuman yang paling sering adalah kelompok yang kalah akan menggendong kelompok yang menang. Pertanyaan pada cecimpedan seputar alam lingkungan, tidak boleh menggunakan bahasa lndonesia, jawaban menyangkut ranah tradisional, dan tidak boleh menggunakan benda benda yang mengacu ke ranah modern. Dalam perkembangannya, karya sastra lisan yang berupa Paribasa Bali ini memiliki nilai moral yang sangat kuat bagi para pembacanya, tetapi untuk meningkatkan minat baca para generasi muda, pengajar harus memiliki cara-cara jitu untuk mengemas bahasa Bali agar lebih menarik. Salah satunya dengan menggunakan permainan cecimpedan sebagai sarana bermain sambil belajar kosa kata bahasa Bali serta sarana untuk memperkenalkan lingkungan sekitar. Seperti yang disajikan pada pendahuluan, bahwa dewasa ini cecimpedan sering dilombakan. Cecimpedan, berasal kata dari 'cimped', lalu direduplikasikan menjadi 'cecimped', lalu mendapat akhiran (pangiring) - an menjadi 'cecimpedan' yang artinya terka-terkaan (bade-badean) yang juga umum disebut teka-teki, gunanya untuk mengasah otak.

Cecimpedan merupakan kerarifan lokal masyarakat Pulau Dewata yang teka-tekinya dibawakan secara lisan saat anak-anak tengah bermain. Untuk lebih menarik minat anakanak menekuni seni tradisi ini harus dikemas dengan seni pertunjukan, dengan catatan saat mereka melontarkan pertanyaan diiringi dengan tembang sehingga lebih menarik, lebih segar, dan tidak monoton tanpa menghilangkan inti cecimpedan tersebut. Meski diberikan sentuhan segar melalui seni pertunjukan, namun hal itu tidak melabrak tradisi cecimpedan sebagai tradisi menerka khas Bali. Pada umumnya di Bali kita mengenal beberapa jenis cecimpedan, seperti di bawah ini.

\section{Cecimpedan Alit-Alit}

Cecimpedan ini digunakan untuk mengasah kemampuan anak dalam penguasaan pembendaharaan kosa kata bahasa Bali. Bentuk cecimpedan ini biasanya berupa kalimat pendek dan jawabannya biasanya bersajak daripada ungkapan tersebut.

Misalnya:

Apa cing- sok?

Jawabnya:

- Cicing ngamah sok.

- Cicing mewadah sok. 
Universitas Hindu Negeri I Gusti Bagus Sugriwa

Denpasar

http://ejournal.uhnsugriwa.ac.id/index.php/ppg

Volume. 2, Nomor 1 Mei 2021; e ISSN: 2722-8614

\section{Cecimpedan Lumrah}

Cecimpedan ini biasanya lumrah dimainkan oleh anak-anak di atas umur 10 tahun. Bentuk cecimpedan ini berupa kalimat tanya yang mempergunakan kata 'apa', 'apa ke' di awal kalimatnya dan hanya memiliki satu jawaban pasti.

Misalnya:

- Apa anak cerik matapel ? (blauk)

- Apa anak cerik pantigang ngurek gumi ? (gangsing)

- Apa cekuk kejengitin? (caratan)

- Apa ngamah uli bungut, mamunyi ditundu? (jangkrik)

- Apa mmemene matujuang panakne nguber ? (bedil)

- Apa keplag-keplug pesu bulan dadua? (ngempug nyuh)

- Apa anak cenik ileh-ileh ngaba api ? (kunang-kunang)

- Apa anak cerik dueg ngukir? (tetani)

- Apa yen dendeng belus? (lengar)

- Apa anak cenik matatu di basang ? (kulkul)

- Apa tolih tolih ngejohang ? (kuping)

- Apa uber ngejohang ? (lawat)

- Apa dituune puyung dimenekne misi ? (anak neku yeh)

- Apa tusing pegat baan nyepeg? (yeh)

- Apa anak cenik ngigel ngedeng tali ? (layangan)

- Apa ulung beten alihin baduur? (umah tuduhan)

- Apa nasi maulat ? (entip)

- Apa anak cenik dimedemne magantung ? (lelawah).

- Apa dicenikne mabaju gadang dikelihne mabaju barak? (buluan)

- Apa taluhne matanem inane magedi ? (penyu)

- Apa ngamah di duur meju diduur? (kutu)

- Apa anak ganggas keiterin gonding ?(punyan nyuh)

- Apa gong dimalu, umbul-umbulne duri ? ( cicing)

\section{Cecangkriman}

Cecimpedan yang menggunakan nyanyian disebut dengan Cecangkriman. Cecangkriman ini sebenarnya tidak lain ialah syair teka-teki. Syair ini biasanya dinyanyikan menggunakan tembang pucung.

Misalnya:

(1) Kaki pucung, awak bunter maretungtung, basangne anginan, asing paek ye ninjakin, 
Universitas Hindu Negeri I Gusti Bagus Sugriwa

Denpasar

http://ejournal.uhnsugriwa.ac.id/index.php/ppg

Volume. 2, Nomor 1 Mei 2021; e ISSN: 2722-8614

uber kepung,

$i$ kaki incang-incangan

(tebakannya : maplalian sepak bola )

(2) Kaki pucung,

manumadi di alas arum,

bengkut pangadegnya,

awakne mabulu pipis

tua cakluk,

layahne selep-selpang

(tebakannya $:$ klesih $=$ trenggiling)

(3) Muncuk duur.

jelegane berag landung,

rainnyane dadua

ngelah awak ye akatih

apa iku

melahang cening manarka

(tebakannya : keris)

(4) Ada taru,

ngelah gondong cenik liu

tegeh miwah ganggas,

buahne maguna gati,

yan matemu,

pasti kayun matumbasan.

(tebakannya : punyan nyuh)

Selain untuk mempelajari kosa kata bahasa Bali, permainan cecimpedan juga melatih anak-anak dalam belajar berimajinasi dengan membayangkan isi dari teka-teki dan mengaitkannya dengan lingkungan sekitar. Tak jarang, bermain cecimpedan juga mejadi suatu sarana dalam memperkenalkan lingkungan sekitar kepada anak-anak, baik dari segi tanaman yang tumbuh di sekitarnya, hewan yang hidup di sekitar, juga berbagai perabot rumah tangga yang lumrah digunakan dalam kehidupan sehari-hari. Semua isi teka-teki tersebut, tentunya menggunakan kosa kata bahasa Bali. Misalnya seperti cecimpedan di bawah ini.

(1) Apa donne serining-serining buahne lengkong arit? 


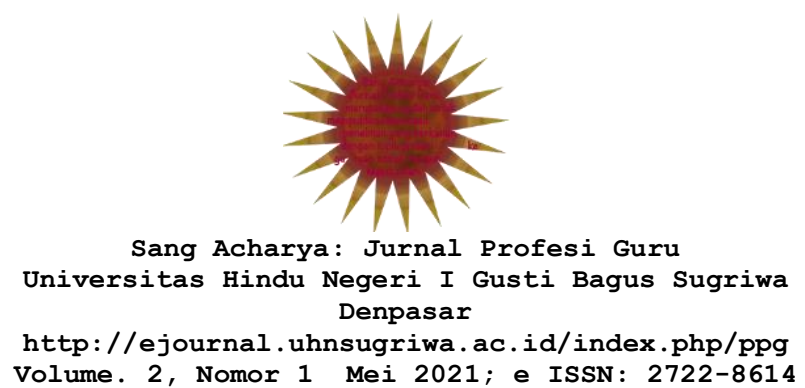

Apa donne serining-serining buahne lengkong arit? (Apa daunnya kecil-kecil buahnya bengkok seperti sabit?), jawabannya adalah lunak (asam). Anak-anak banyak yang tahu asam karena fungsinya banyak seperti dipakai campuran bumbu rujak, membuat sayur asam, dan mengasami ikan segar agar gurih ketika dimasak dan mengurangi rasa amis. Walaupun demikian, banyak pula anak-anak kita tidak tahu pohon asam. Para orang tua akan menjelaskan pohon asam itu tinggi besar, daunnya kecil-kecil dan buahnya selalu bengkok menyerupai sabit. Dalam hal ini, ada dua kata sekalian yang dijelaskan di samping asam tadi, anak-anak terutama yang lahir di kota, banyak yang tidak tahu arit. (sabit). Di sini akan dijelaskan fungsi sabit (arit) bagi para petani. Dengan demikian, wawasan anak-anak akan bertambah.

\section{(2) Apa cekuk kajengitin?}

Apa cekuk kajengitin? (Apakah dicekik lalu diseringai?), jawabannya adalah caratan (nginum yeh aji caratan) (minum air dengan kendi). Caratan merupakan alat minum air tradisional yang dibuat dengan tanah. Benda ini kini telah langka dan kosakata caratan dalam bahasa Bali telah menjadi kata arkais. Cara minumnya harus dicekik, diangkat, kemudian airnya dijaga dengan mulut terbuka, tidak dengan mengulum lubang tempat airnya keluar. Benda ini semakin menghilang dengan hadirnya alat minum yang lebih modern seperti teko (morong) yang terbuat dari seng atau plastik dan cara minum airnya dituangkan ke dalam gelas. Pada saat macecimpedan, kebanyakan anak-anak tidak bisa menjawab, atau bisa menjawab karena mereka pernah mendengar soal seperti itu, tetapi tidak tahu wujud benda tersebut. Di sinilah peranan orang tua menjelaskan dan memeragakan seadanya. Dengan demikian, melalui permainan cecimpedan ini sesungguhnya membuka wawasan anak-anak dengan situasi alam tadisional zaman dahulu. Bagaimana para olang tua kita hidup sederhana, jika haus cukup dengan minum air putih yang tersedia di setiap rumah tangga.

\section{(3) Apa soroh jukung masasah bintang?}

Apa soroh jukung masasah bintang? (Apakah dorong sampan berserakan bintang?), jawabannya adalah anak mamula padi (orang menanam padi). Secara tradisional, para petani ketika menanam padi di sawah secara tradisional akan memakai sarana tempeh (nyiru kecil) tempat bibit tanaman padi. Bibit ini akan ditanam dengan berjalan mundur. Tempeh itu diibaratkan jukung dan sawah yang berlumpur diumpamakan laut. Cara menanarnnya si petani akan berjalan mundur, tempeh digeser ke belakang dengan kaki. Jadi, yang ada di hadapan penanam itu adalah tanaman bibit padi berjajar diibaratkan bintang-bintang. Di sini anak-anak akan memperoleh wawasan cara bertanam padi serta alat tempeh yang semakin langka. Para orang tua dapat menambahkan sebagai nasihat pada anak agar irit-irit makan dan jangan suka membuang nasi karena begitulah susah payahnya para petani menanam padi. 


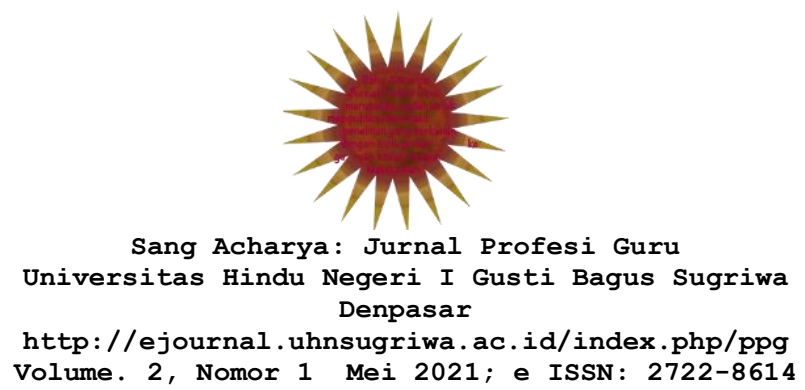

Mereka di bawah terik matahari dan kaki terendam lumpur bekerja demi kita bisa makan nasi beras.

\section{(4) Apa mamua telu mabatis dasa?}

Apa mamua telu mabatis dasa? (Apakah berkepala tiga danberkaki sepuluh?), jawabannya adalah anak nengala (orang membajak di sawah atau ladang). Kepala tiga, yaitu satu kepala si pembajak dan dua kepala lagi adalah kepala sapi/kerbau. Kakinya berjumlah sepuluh adalah delapan kaki sepasang sapi/kerbau dan dua kaki si pembajak. Alat membajak terdahulu memakai sepasang sapi atau kerbau, kini telah tergantikan dengan alat modern, yaitu traktor. Penggantian ini membawa implikasi anak-anak kita semakin tidak mengenal kata nengala (membajak). Lebih-lebih lagi pengaruh globalisasi berdampak keras pada beralih fungsinya lahan pertanian. Walaupun demikian, masih ada sawah-sawah yang bertahan dengan pengolahan tradisional, bahkan membawa rezeki karena menjadi konsumsi pariwisata. Melalui cecimpedan anak-anak akan memperoleh banyak wawasan lingkungan tradisional yang semakin terimpit arus mordenisasi. Para orang tua dapat melanjutkan kosakata terkait yang sudah masuk kosa kata bahasa Bali arkais, seperti uga (palang pemegang dan pengikat kedua sapi), tengala (alat pembajak), kejen (pisau pembelah tanah), dan camok (keranjang kecil dari bambu sebagai penutup mulut sapi/kerbau agar tidak makan rumput ketika membajak).

\section{(5) Apa punyane gede mabuah cenik, punyane cenik mabuah gede?}

Apa punyane gede mabuah cenik, punyane cenik mabuah gede? (Apakah pohonnya besar buahnya kecil, pohonnya kecil buahnya besar?). Untuk jawaban pertanyaan pertama adalah punyan bingin (pohon beringin) dan dari pertanyan kedua adalah tabu/waluh (labu). Anak-anak mempunyai pertanyaan seperti ini biasanya mereka peroleh dari orang tua atau di dalam buku. Terkait dengan pertanyaan dan jawaban di atas, anak-anak akan memperoleh tambahan wawasan tentang punyan bingin (pohon beringin) dan tabu/waluh (labu). Pohon beringin biasanya hidup di halaman pura, di tempat-tempat keramat di hutan, atau di pekarangan balai desa. Pohonnya tinggi besar sangat cocok dipakai peneduh. Walaupun demikian, pohon beringin rawan tumbang ketika ada angin kencang. Hal ini yang biasanya dijelaskan oleh orang tua kepada anak-anak saat dipakai soal dalam macecimpedan. Di samping itu, juga kegunaan pohon beringin yang lain yang terkait dengan kehidupan sosial budaya, seperti sarana upacara ngaben dan obat impoten (Nala,

2002 : 226). Kini pohon beringin sudah menjadi langka karena ditebang ketika tumbuh sembarangan. Masyarakat takut nanti pohon beringin itu akan menjadi besar dapat mengganggu tanaman yang lain dan mudah tumbang ketika ada angin kencang. Untuk anakanak yang lahir dan besar di kota, jelas tidak akan tahu pohon beringin tersebut. Dengan bermain cecimpedan akhirnya mereka tahu, paling tidak dapat membayangkan pohon dan buahnya yang kecil-kecil. Sedangkan, labu termasuk jenis tanaman rambat. Batang pohonnya sebesar kelingking orang dewasa dan buahnya besar sebesar kepala manusia, bahkan ada yang lebih besar lagi. Dahulu hampir setiap ladang di desa ditanami pohon labu karena 


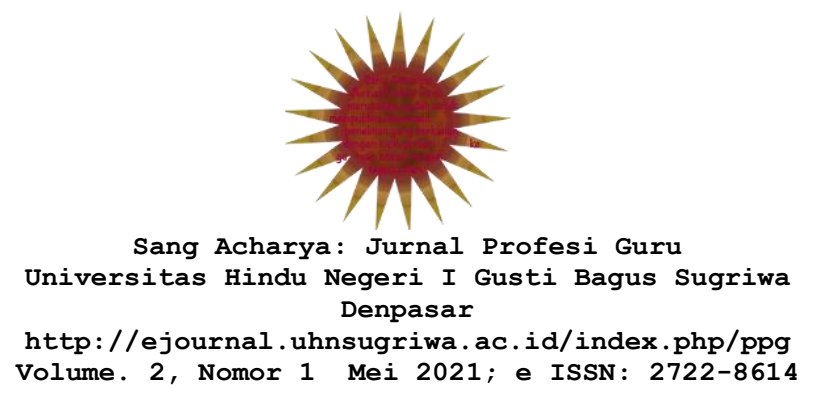

memiliki banyak kegunaan. Pucuk daun dan buahnya yang muda dapat dipakai sayur. Buahnya dapat dikukus atau diolah sebagai teman minum kopi atau teh bagi para petani dan dapat dipakai obat tradisional. Hal ini yang biasanya dijelaskan pada anak-anak ketika mereka kebingungan membayangkan wujud pohon labu tersebut. Kini keadaannya sudah langka. Walaupun masih ada, jelas harganya mahal apalagi buah labu sudah masuk ke pasar swalayan dan menjadi olahan kue bagi pengusaha catering.

Pada cecimpedan nomor (1) sampai (5) di atas merupakan cecimpedan yang sudah dikenal sejak dahulu. Fungsinya antara lain, yaitu menyenangkan anak-anak, melatih ketangkasan berpikir anak-anak secara spontan dan melestarikan kosa kata bahasa Bali agar tidak punah. Belakangan ini banyak cecimpedan yang diciptakan oleh anak-anak, sepertiApake, manyama ajak telu yen panes makeplug saka besik?' (Apakah bersaudara bertiga, jika dipanaskan meledak satu per satu?), jawabannya adalah panimpug (tiga potong bambu diikat, kemudian dipanaskan dengan api digunakan saat upacara macaru). Pertanyaan ini biasanya diajukan oleh anak-anak yang memiliki perhatian pada upacara agama. Selain itu juga ada cecimpedan 'Apa ke teka anak gede, kamenne kober, gumine majalan?' (Apakah itu, datang orang besar, kainnya berkibar, dunia berjalan?), jawabannya adalah bidak perahu layar,. cecimpedan ini diajukan oleh anak-anak yang ada di pesisir pantai. Pada kedua cecimpedan di atas menunjukkan bahwa anak-anak dilatih berpikir kreatif untuk menciptakan cecimpedan yang baru. Di samping itu, dengan terciptanya cecimpedan yang diciptakan anak-anak yang berasal dari latar belakang sosial atau daerah berbeda, mereka akan bertukar pengetahuan. Dengan demikian fungsi lain dari cecimpedan adalah menambah wawasan lingkungan bagi anak-anak.

\section{Penutup}

Bahasa Bali merupakan salah satu bahasa daerah yang sampai saat ini masih digunakan oleh masyarakat penuturnya. Kesusastraan Bali adalah hasil karya atau cipta seorang pengarang atau pujangga yang menceritakan dinamika kehidupan masyarakat Bali serta mengandung nilai estetika yang menggunakan bahasa sebagai mediumnya. Masyarakat Bali juga memiliki berbagai bentuk sastra lisan. Sastra lisan yang cukup dikenal adalah Basita Paribasa Bali. Pembagian Basita Paribasa Bali merurut para ahli dibagi menjadi beberapa bentuk. Salah satunya adalah cecimpedan yang juga merupakan tradisi seni masyarakat Pulau Dewata, yang dibawakan secara lisan serta teka-teki yang disampaikan biasanya dimainkan oleh anak-anak. Dalam permainan cecimpedan, anak-anak akan belajar berbagai hal yang berguna untuk meningkatkan kemampuan berimajinasi dan kecerdasan anak. Beberapa hal yang akan diperoleh ketika bermain cecimpedan, anak-anak dapat belajar kosa kata bahasa Bali secara tidak langsung, belajar imajinasi dengan membayangkan isi dari teka-teki dan mengaitkannya dengan lingkungan sekitar, meningkatkan kecerdasan anak melalui proses bermain yang menyenangkan (bermain sambil belajar), belajar mengemukakan pendapat (bersosialisasi) serta berkompetisi dengan rekan sepermainan. 


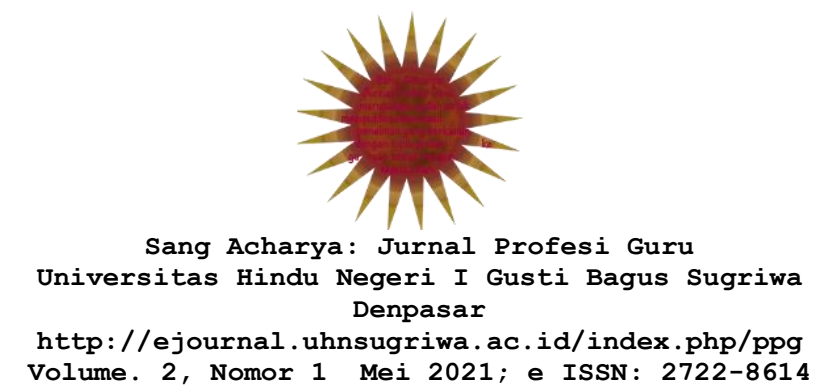

Dengan demikian, permainan cecimpedan dapat dijadikan sebagai sarana bermain, belajar kosakata bahasa Bali serta sebagai media sederhana dalam mengenali lingkungan sekitar.

\section{Daftar Pustaka}

Anom, I Gusti Ketut dkk. 2014. Kamus Bali-Indonesia Beraksara Latin dan Bali. Denpasar:

Badan Pembina Bahasa, Aksara dan Basaha Bali Provinsi Bali.

Bawa, I Wayan. 1981. Pemakaian Bahasa Indonesia yang Baik dan Benar. Denpasar: Jurusan Bahasa dan Sastra Indonesia Fakultas Sastra Universitas Udayana.

Bongaya, I W. S. A. 2016. Basita Paribasa. Denpasar: Upada Sastra.

Nala, Ngurah. 2002. Usada Bali. Denpasar: Upada Sastra.

Simpen, A.B, W. 2010. Basita Parihasa. Denpasar: Upada Sastra.

Tinggen, I N. 1988. Aneka Rupa: Paribasa Bali. Singaraja: Rhika Dewata. . 2005 . Cecimpedan lan Beladbadan. Singaraja: Indra Jaya. 